\title{
Integrated Frequency Control of Microhydro Power Plant Based Flow Valve Control and Electronic Load Controller
}

\author{
Zulfatman Has \\ Electrical Engineering Department \\ University of Muhammadiyah Malang \\ zulfatman@umm.ac.id \\ Nur Alif Mardiyah \\ Electrical Engineering Department \\ University of Muhammadiyah Malang \\ nuralif@umm.ac.id
}

\author{
Alwan Zanuar Rosyidi \\ Electrical Engineering Department \\ University of Muhammadiyah Malang \\ alwanzanuar@webmail.umm.ac.id \\ Nurhadi Nurhadi \\ Electrical Engineering Department \\ University of Muhammadiyah Malang \\ nurhadi@umm.ac.id
}

\author{
Ilham Pakaya \\ Electrical Engineering Department \\ University of Muhammadiyah Malang \\ ilhampakaya@umm.ac.id \\ Machmud Effendy \\ Electrical Engineering Department \\ University of Muhammadiyah Malang \\ machmudeffendy@umm.ac.id
}

\begin{abstract}
Frequency instability is one of the main problems in generating Micro-hydro Power Plant (MHPP) with synchronous generator. Governor control using Flow Valve Control (FVC) and Electronic Load Control (ELC) are the common methods that have been applied for MHPP frequency control. However, slow time response and relatively high total harmonic distortion (THD) problems are still exist in the system output when the load vary significantly. FVC is very slow in time response, but produce low THD. In the contrary, ELC very fast in response, but results relatively high THD. This study proposes control techniques for FVC and ELC in order to improve time response and to result a lower THD level. FCV is controlled by Fuzzy-Proportional Integral (Fuzzy-PI) controller to improve the time response, while ELC is improved by Adaptive Neuro Fuzzy Inference System-Proportional Integral Differentia (ANFIS-PID) controller to reduce the load variation effect on THD level. The ELC circuit employs 3 phase rectifier circuit. The ELC circuit is driving current through load bus to load ballast. These integrated controller is simulated by using Matlab Simulink. Results of simulation indicate that by deploying the proposed controller on the FVC and the ELC, respectively and by integrating them all together, the time response and the THD of the MHPP output are improved in the load changes.
\end{abstract}

Keywords - microhydro, synchronous generator, frequency, governor, electronic load controller, load changes

\section{INTRODUCTION}

Micro-hydro Power Plant (MHPP) is electricity generation system that utilities the difference of water level of river flow. One of the most important things that must be maintained in producing electrical energy is how to control the MHPP generator rotating constantly to guarantee frequency of generation remains stable even though the load needs change [1].

A common technique that has been widely used to maintain frequency stability in MHPP is to use the governor system. The governor works by regulating the flow of water entering the turbine to rotate the generator. The frequency produced by the generator is directly proportional to the turbine rotational speed [2]. Control of the water flow is done by opening the gate on the penstock using a servo motor. To get the right angle for the gate opening based on system requirements, the servo motor rotation angle must be adjusted. Settings are made to push the actual value and frequency reference has the smallest possible error. This error value and motor response must be minimized by adding the appropriate controller.

The earliest study designed for regulating the governor system was based on the PID controller. But at the results of the output are still found weaknesses, such as the occurrence of a long enough oscillation at the output before going to the steady state area [3]. To overcome these problems, the governor control technique based on Fuzzy Logic Controller (FLC) was developed [4]. This method can reduce oscillation, but with very slow response. Another effort that has been done is to combine fuzzy methods with conventional Proportional Integral (PI) controllers to provide an increase in system response [5]. In the existence of fuzzy, PID parameters are made to be more able to adapt to changes in load. The following methods were Adaptive Fuzzy-PID [6] and Robust $\mathrm{H} \infty$ Control [7]. However, the control techniques were only prepared for small change of load. From several studies above the main problem seen in governor-based frequency regulation is the slow response given by the governor system to return the frequency back to its original frequency when a load change occurs, especially for sudden significant changes.

An alternative platform in MHPP frequency control that has been developed intensively during the last decade is Electronic Load Control (ELC). The ELC consists of threephase rectifier circuit, which on one hand is able to accelerate frequency recovery significantly, but can cause a fairly high harmonic level at the generator output [8]. ELC is used to absorb power with large changes. The ELC circuit works by diverting current on the load bus to ballast load. The ELC circuit requires a control technique to determine the amount of current flowing into ballast load.

The initial research that has been carried out regarding ELC was the PI controller [9]. Another development was rectifier control using the fuzzy-PI control technique [10]. The results of these studies show that fuzzy-PI has dynamic and static performance that is better than traditional PI control techniques. Another type of arrangement technique that has been developed was PSO-based PI controller [11]. If the last two control techniques are compared, although the PSO can produce slightly better performance than fuzzy, fuzzy is still easier to design and operate, especially when applied to the actual system.

However, fuzzy techniques have vulnerability, such as in terms of determining the inference model that is still done manually, and does not have the ability to make predictions. 
The combination of neural network and fuzzy is an alternative solution to overcome the weakness of fuzzy system design. Adaptive Neuro Fuzzy Inference System (ANFIS) is a combination of two methods, fuzzy logic and neural network. In this method the neural network has the advantage of being able to predict future events based on input data [9]. When the PID controller is combined with ANFIS, it is expected that it will further enhance the ability of the ELC system to adapt to changes in load, which will help the MHPP to produce a lower THD level. Thus the purpose of this study is to optimize the frequency response for the load changes in the MHPP by integrating Fuzzy-PI-based governor (Flow Valve Control) controls and ANFIS-PID based ELC series. This combination is an improvement over the combination in the previous study [12].

\section{Methodology}

\section{A. Hydraulic Turbine Model}

Model of hydraulic turbine is expressed as in Fig. 1 below.

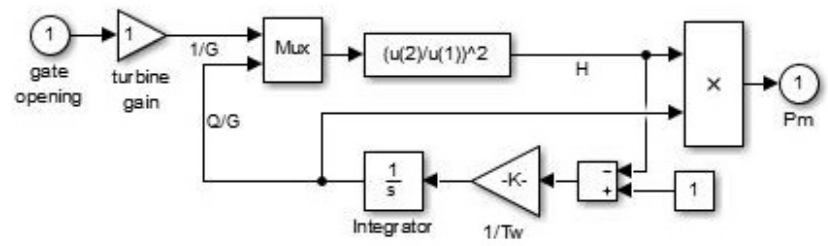

Fig. 1. Hydraulic turbine Simulink model

While parameters of the hydraulic turbine is listed as in Table 1.

TABLE I. HydRAULIC-TuRBINE PARAMETERS

\begin{tabular}{|l|c|c|}
\hline \multicolumn{1}{|c|}{ Parameter } & Symbol & Value \\
\hline Turbine Flow & $Q_{t}$ & $0.95 \mathrm{~m}^{3} / \mathrm{s}$ \\
\hline Base Head & $h_{\text {base }}$ & $16.74 \mathrm{~m}$ \\
\hline Penstock Area & $A$ & $0.389 \mathrm{~m}^{2}$ \\
\hline Length Penstock & $L$ & $60 \mathrm{~m}$ \\
\hline Gravity & $g$ & $9.8 \mathrm{~m} / \mathrm{s}^{2}$ \\
\hline Turbine Gain & {$\left[\mathbf{G}_{\max }, \mathbf{G}_{\min }\right]$} & {$[1,0]$} \\
\hline
\end{tabular}

\section{B. Hydro-electric Servo System Model}

Servo motor is employed to control the opening gate that ensures flow rate of the water source is remain constant. Model of the hydro-electric servo system is depicted as in Fig. 2.

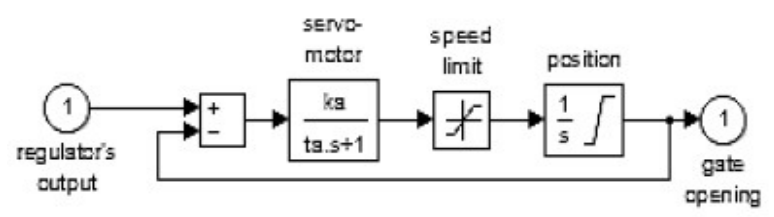

Fig. 2. Hydro-electric servo system Simulink model

TABLE II. HydRO-ELECTRIC SERVO SYSTEM PARAMETERS

\begin{tabular}{|l|c|c|}
\hline \multicolumn{1}{|c|}{ Parameter } & Symbol & Value \\
\hline Gain constant of motor servo & $k_{a}$ & $0.95 \mathrm{~m}^{3} / \mathrm{s}$ \\
\hline Time constant of motor servo & $t_{a}$ & $16.74 \mathrm{~m}$ \\
\hline Speed limit & {$\left[\mathbf{V} \mathbf{g}_{\min }, \mathbf{V} \mathbf{g}_{\max }\right]$} & {$[-1,1]$} \\
\hline
\end{tabular}

\section{Governor Model}

When the hydraulic-turbine and the hydro-electric servo motor systems are included in governor system, the governor model can be expressed as in Fig. 3 .

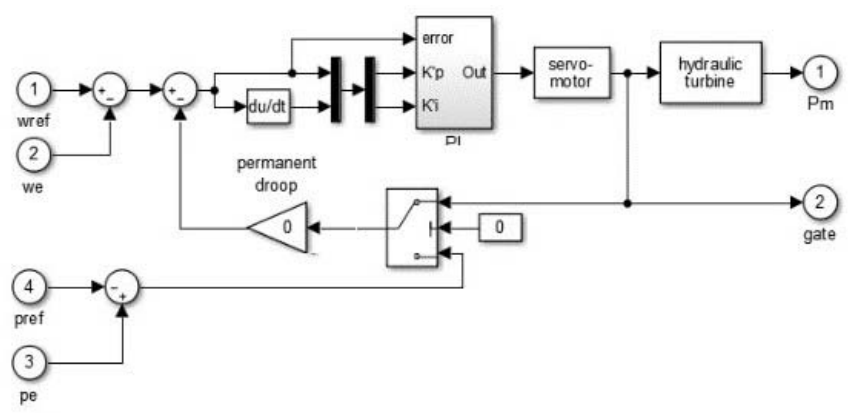

Fig. 3. Simulink Model of Governor

As can be seen in Fig. 3, PI controller is basic controller that applies to the governor system to guarantee the frequency in its normal frequency when there are some changes in load during operating condition.

\section{Fuzzy-PI Design}

Configuration of the control system is based on the Fuzzy-PI control technique. There are two fuzzy inputs, the error value $e(t)$ and the first derivative of the error value $d e(t)$, with two outputs for each parameter from the PI controller, $K p$ and $K i$. The values of each variable are determined based on the preliminary simulation on the system model with the best parameters of a PI controller.

In the proposed design, the membership function of the input is divided into 5 levels of fuzzy linguistic variables as shown in Fig. 4. The linguistic variables used are NB: Negative Big, NS: Negative Small. Z: Zero, PS: Positive Small, and PB: Positive Big.

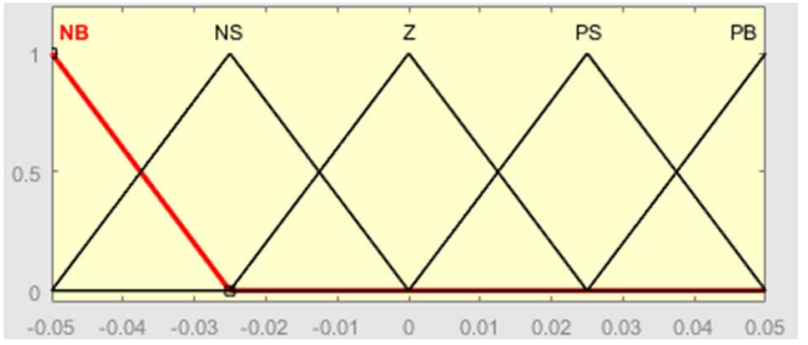

Fig. 4. Membership function of $e(t)$ and $d e(t)$

While membership function of fuzzy output for $K^{\prime} p$ dan $K^{\prime} i$ is depicted as in Fig. 5. Linguistic variables for the output are labelled as: S: Small, MS: Medium Small, M: Medium, MB: Medium Big, B: Big, in which range of values from 0.05 to 0.05 .

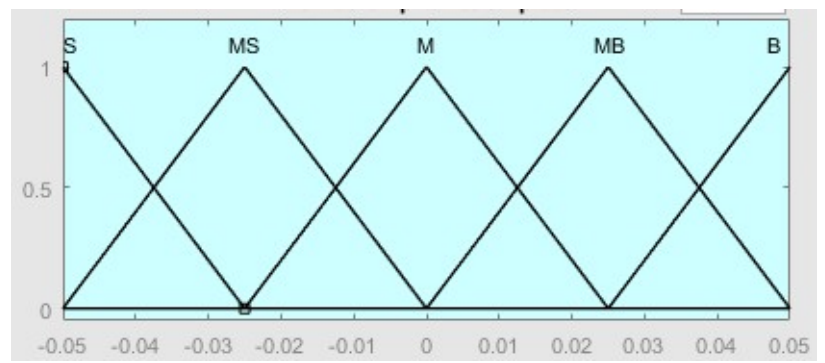

Fig. 5 Membership function of $K^{\prime} p$ and $K^{\prime} i$

In this study, the fuzzy system is employed with 5 linguistic variables for both input and output, such that this design totally uses 25 fuzzy rules as stated in Table III. 
TABLE III. FUZZY RULES

\begin{tabular}{|c|c|c|c|c|c|}
\hline $\boldsymbol{e} / \boldsymbol{d} \boldsymbol{e}$ & NB & NS & $\mathbf{Z}$ & PS & PB \\
\hline NB & S & S & MS & MS & M \\
\hline NS & S & MS & MS & M & MB \\
\hline Z & MS & MS & M & MB & MB \\
\hline PS & MS & M & MB & MB & B \\
\hline PB & M & MB & MB & B & B \\
\hline
\end{tabular}

\section{E. Electronic Load Controller Design}

ELC design for this study consist of rectifier as main component. Another component of the ELC is mosfet that is composed for 3 phase model as seen in Fig. 6 below.

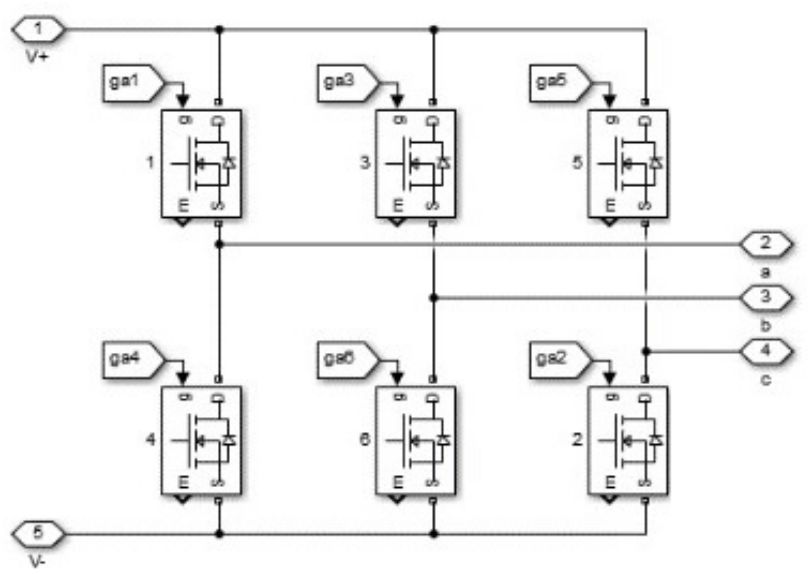

Fig. 6. Rectifier design

In the simulation of the proposed design, parameters of the mosfet uses the default values of the Matlab Simulink.

\section{F. ANFIS Design}

ANFIS-PID control scheme is constructed by using Matlab Simulink. Fig. 7 shows general design of the ANFISPID controller. Architecture of the ANFIS is an adaptive network that trains the network under supervised learning method by using a learning algorithms, which has functions similar to the Takagi-Sugeno fuzzy inference system model.

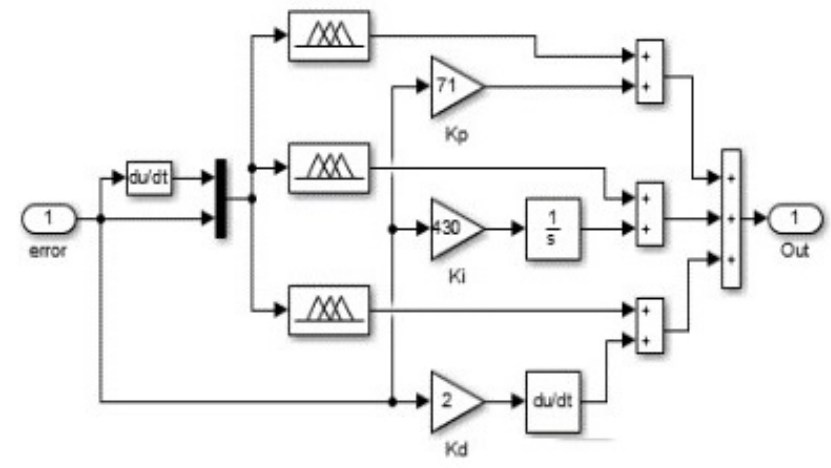

Fig. 7. Simulink block of ANFIS-PID controller

Detail design of the ANFIS is depicted in Fig. 8. In order to simplify the ANFIS system, it can be designed in two inputs: $x$ and $y$, and one output: $f$. Two rules in "If-Then" relation are prepared by using Takagi-Sugeno model, as stated in equation (1) and (2) below:

Rule $1=$ If $x$ is $A_{1}$ and $y$ is $B_{I}$

Then $f_{1}=p_{1} x+q_{1} x+r_{1}$

Rule $2=$ If $x$ is $A_{2}$ and $y$ is $B_{2}$

$$
\text { Then } f_{2}=p_{2} x+q_{2} x+r_{2}
$$

where $\mathrm{A} 1, \mathrm{~A} 2, \mathrm{~B} 1, \mathrm{~B} 2$ respectively membership function of inputs $x$ and $y$. While $\mathrm{p} 1, \mathrm{q} 1, \mathrm{r} 1$ and $\mathrm{p} 2, \mathrm{q} 2, \mathrm{r} 2$ are linear parameters in the part due to the Takagi-Sugeno fuzzy inference model.

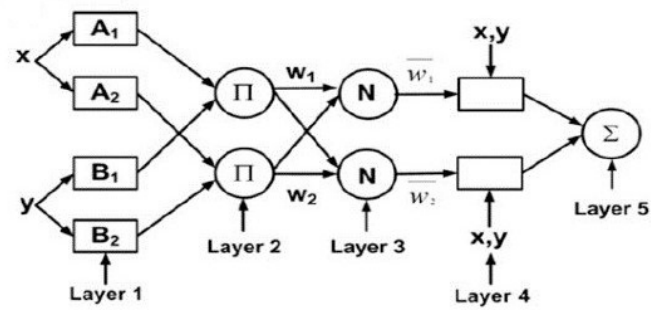

Fig. 8. ANFIS architecture

In the ANFIS design, input of the ANFIS are defined as $e(t)$ dan $d e(t)$, in which values of $e(t)$ dan $d e(t)$ are employed as values for data training of neural network. Training process of ANFIS to obtain values for $K p, K i$ dan $K d$ of output is designed in a specific algorithm.

\section{G. Ballast Load and Consumer Load Designs}

Ballast load for the MHPP system is designed as in Fig. 9. Load, frequency, and Vrms are set in $82 \mathrm{KW}, 50 \mathrm{~Hz}$, and $400 \mathrm{~V}$, respectively. While design of consumer load consists of resistive and inductive loads as depicted in Fig. 10 below.

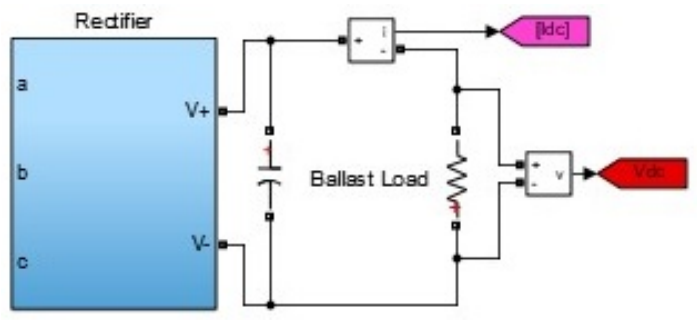

Fig. 9. Ballast load design

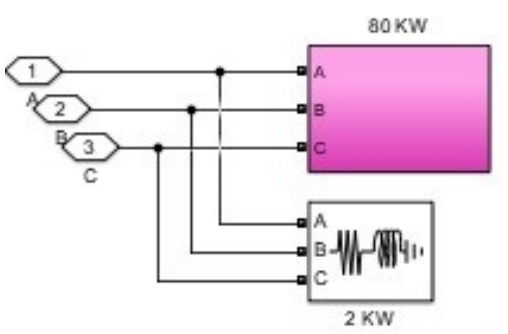

Fig. 10. Consumer load design

\section{H. Synchronous Generator Model}

This study deals with three phase synchronous generator. Mathematical model of the generator is developed by Park's transformation that are well known as $d-q$ transformation [13]. Parameters of the model are listed in Table IV.

TABLE IV. SYNCHRONOUS GENERATOR PARAMETERS

\begin{tabular}{|c|c|}
\hline Parameter & Value \\
\hline $\begin{array}{l}\text { Nominal (VA), line-to-line voltage }(\mathrm{V}) \text {, } \\
\text { frequency }(\mathrm{Hz})\end{array}$ & $160 \mathrm{e} 3,400,50$ \\
\hline $\begin{array}{l}\text { Reactance }\left(X d, X d^{\prime}, X d^{\prime}, X q^{\prime}, X q^{\prime}, X l\right) \\
(p u)\end{array}$ & $\begin{array}{c}{[2.24,0.19,0.13,1.38,} \\
0.17,0.07]\end{array}$ \\
\hline Time Constant [Td',Td",Tq"] (sec) & {$[0.035,0.011,0.011]$} \\
\hline Stator Resistance (pu) & 0.024 \\
\hline $\begin{array}{l}\text { Inertia coefficient (s), friction factor } \\
(\mathrm{pu}) \text { pole pairs }\end{array}$ & {$\left[\begin{array}{lll}8 & 0 & 4\end{array}\right]$} \\
\hline Rotor Type & Salient-Pole \\
\hline
\end{tabular}




\section{Excitation System}

Excitation system of the generator in the study uses AVR AC4A model that referred to IEEE standard [14] that has been prepared in Matlab Simulink. Parameters of the excitation system can be found in Table V.

TABLE V. EXCITATION SYSTEM PARAMETERS

\begin{tabular}{|l|c|}
\hline \multicolumn{1}{|c|}{ Parameter } & Value \\
\hline $\operatorname{Tr}(\mathrm{s})$ & $20 \mathrm{e}-3$ \\
\hline$[\mathrm{Ka}(\mathrm{pu}), \mathrm{Ta}(\mathrm{s})]$ & {$\left[\begin{array}{lll}200 & 0.015\end{array}\right]$} \\
\hline$[\mathrm{Kc}(\mathrm{pu}), \mathrm{Tc}(\mathrm{s})]$ & {$\left[\begin{array}{lll}-10 & 10\end{array}\right]$} \\
\hline $\mathrm{Tb}(\mathrm{s})$ & {$\left[\begin{array}{lll}10 & 1.0\end{array}\right]$} \\
\hline$[\operatorname{vimax}, \operatorname{Vimin}](\mathrm{pu})$ & {$\left[\begin{array}{lll}-10 & 10\end{array}\right]$} \\
\hline$[\operatorname{vrmax}, \mathrm{Vrmin}](\mathrm{pu})$ & {$\left[\begin{array}{cc}-4.53 & 5.64\end{array}\right]$} \\
\hline
\end{tabular}

\section{RESULTS AND DISCUSSION}

\section{A. ELC with Load Changes}

By assuming the load changes, the ELC test results on the MHPP system can be seen from the phase to ground of rms voltage $\left(V_{r m s}\right)$ and the phase to ground of rms current $\left(I_{r m s}\right)$ produced, as in Fig. 11 (a) and (b).

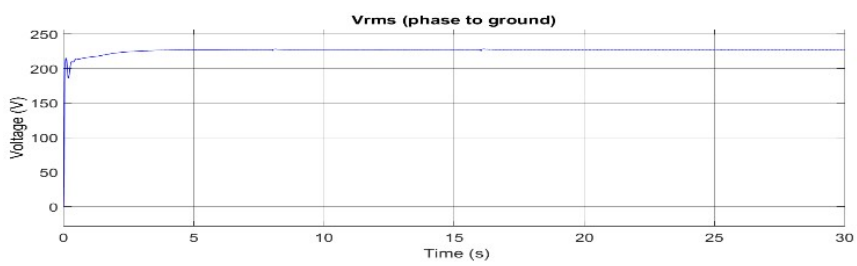

(a)

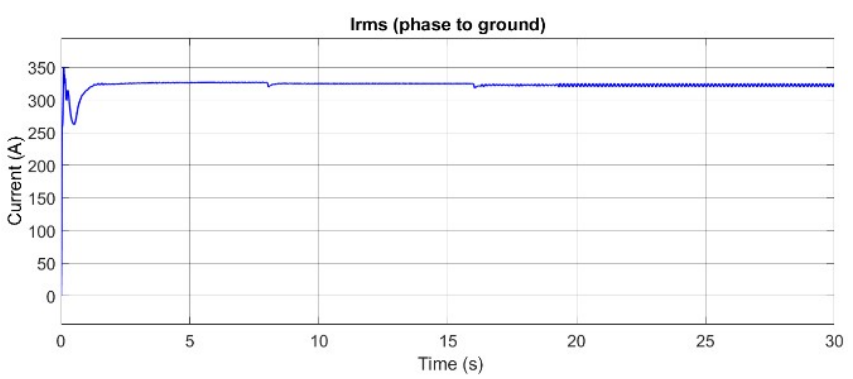

(b)

Fig. 11. (a) Vrms phase to ground (b) Irms phase to ground

In Figures 11 (a) and (b), it can be seen that the ELC system is capable of producing relatively stable $V_{r m s}$ phase to ground and $I_{r m s}$ phase to ground, that is, $230 \mathrm{~V}$ and $325 \mathrm{~A}$, even though there are two changes in consumer load.

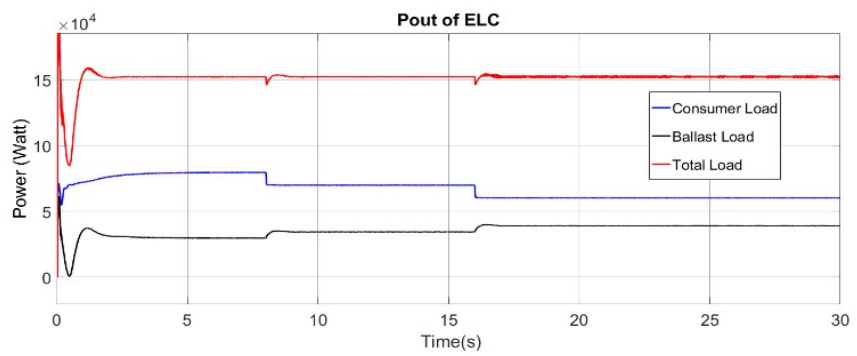

Fig.12. Output power of the MHPP with ELC

Then if viewed from the side of output power, Fig. 12 illustrates how the ELC system works when a load changes. When there is a decrease in consumer load from $82 \mathrm{KW}$ to $72 \mathrm{KW}$, and then to $62 \mathrm{KW}$, it is seen that ballast load compensated for changes in load on these consumers quickly.
However, as in Fig. 13, the existence of ELC does not affect the mechanical power of the MHPP system.

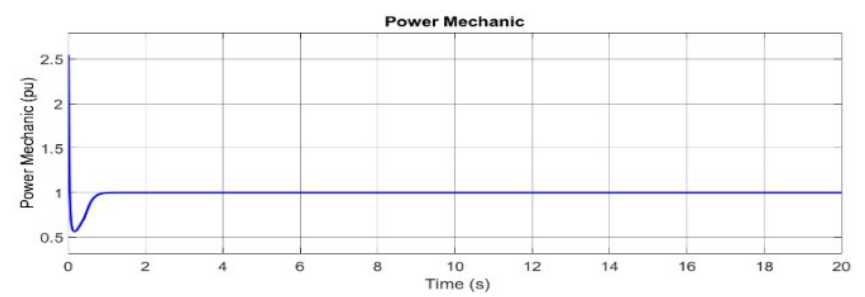

Fig. 13. Mechanical power of the MHPP with ELC

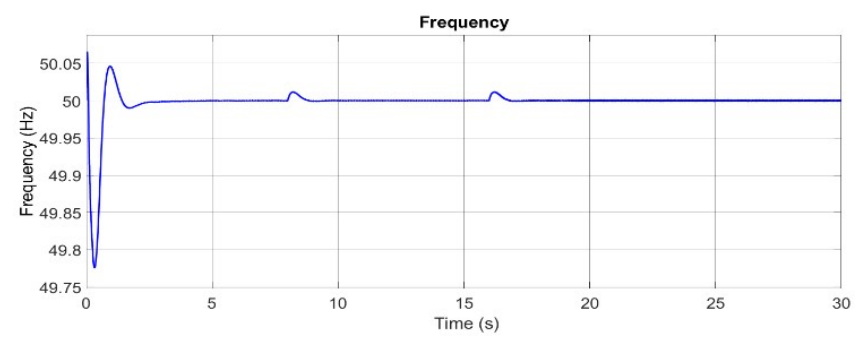

Fig. 14. Frequency of the MHPP with ELC

If an observation is made on the output frequency of the MHPP at Fig. 14, it can be seen that rapid compensation by ballast load causes the frequency produces only $0.025 \mathrm{~Hz}$ per $10 \mathrm{KW}$ of load changes and then returns to its normal frequency quickly in around 1 second. However, the ELC design in this test is only capable of handling load reduction well up to $20 \mathrm{KW}$. In addition, ELC also has a weakness, which is to produce a high THD-I value when ballast load compensates for changes in consumer load. THD-I is calculated by using the following equation.

$$
T H D_{I}=\sqrt{\left(\frac{I_{r m s}}{I_{i}}\right)^{2}-1}
$$

where $I_{i}$ is fundamental current.

The THD-I phenomenon can be explained clearly, that when the load changes, the THD-I value on the ELC system increases the value of the harmonics as shown in Fig. 15. Because a greater ignition angle, produce a greater harmonics. Complete results of ELC testing in three different loads are summarized in Table VI.

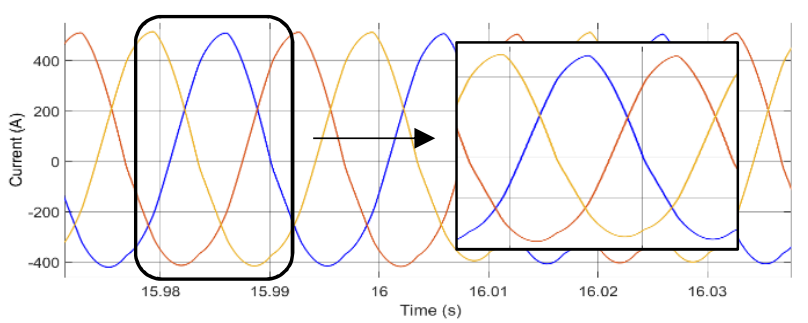

Fig. 15. $2^{\text {nd }}$ THD-I of the MHPP with ELC

TABLE VI. ELC TEST RESUlts

\begin{tabular}{|c|c|c|c|c|c|}
\hline No & $\begin{array}{c}\text { Consumer } \\
\text { Load } \\
(\mathbf{K W})\end{array}$ & $\begin{array}{c}\text { Ballast } \\
\text { Load } \\
(\mathbf{K W})\end{array}$ & $\begin{array}{c}\text { Total } \\
\text { Power } \\
(\mathbf{K W})\end{array}$ & $\begin{array}{c}\text { Mechanical } \\
\text { Power }(\boldsymbol{p u})\end{array}$ & THD -I \\
\hline 1 & 82 & 29.8 & 152 & 1 & $9.88 \%$ \\
\hline 2 & 72 & 34.4 & 152.2 & 1 & $10.59 \%$ \\
\hline 3 & 62 & 39.2 & 152.25 & 1 & $11.74 \%$ \\
\hline
\end{tabular}

B. Integration of ELC and FVC with Load Changes

The results of testing on the MHPP system with the integrated control of ELC and FVC when the load changes can 
be seen from $V_{r m s}$ phase to ground and $I_{r m s}$ phase to ground of the system, as shown in Fig. 16 (a) and (b) below.

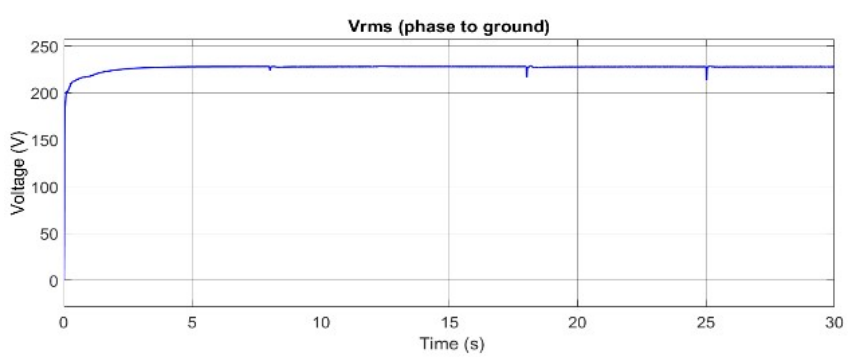

(a)

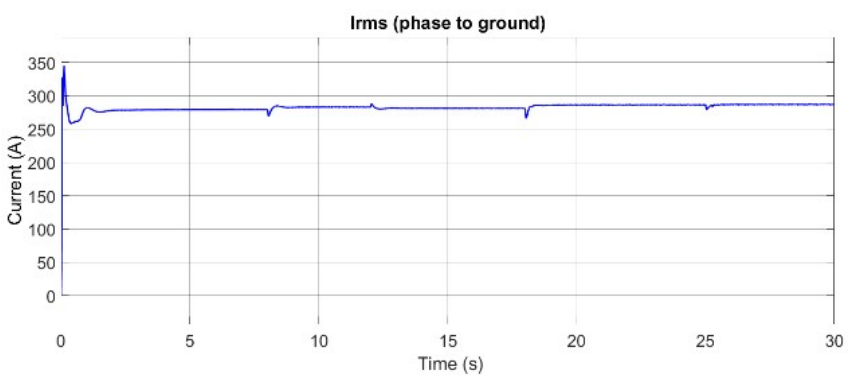

(b)

Fig. 16. (a) Vrms phase to ground (b) Irms phase to ground

From Fig. 16 (a) and (b), it can be seen that the integrated control system is able to produce $V_{r m s}$ phase to ground and $I_{r m s}$ phase to ground $230 \mathrm{~V}$ and $280 \mathrm{~A}$, respectively. By the integrated system, MHPP can work optimally, so there is no significant voltage drop and current drop and can return to the initial value quickly, even though there is a significant decrease in load from $72 \mathrm{KW}$ to $32 \mathrm{KW}$ at $18^{\text {th }}$ second.

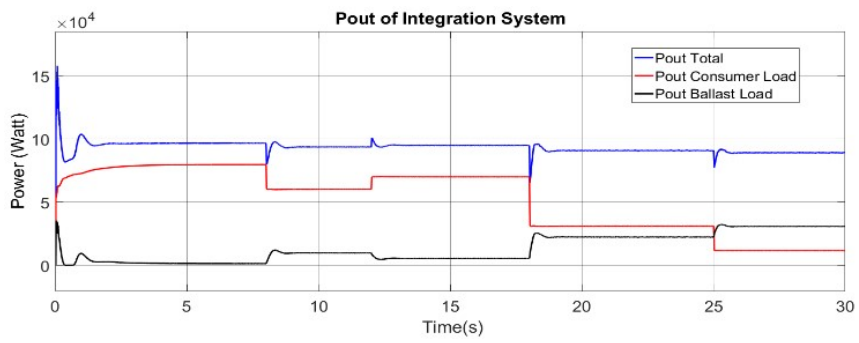

Fig. 17. Output power of the integrated controller

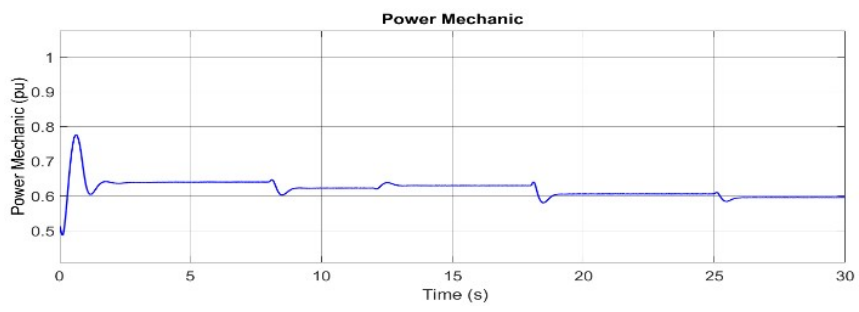

Fig. 18. Mechanical power of the integrated system

Then from Fig. 17, it is seen that the output power of the MHPP declined slightly when there is a significant decrease in load. Special phenomena is also found when the load is very low. Even though the ballast load has provided a large amount of compensation, the power load cannot return to its original power. The same thing is also shown by the mechanical power graph on Fig. 18. However, as shown in Fig. 19, the phenomenon in Fig. 17 and Fig. 18 does not affect the frequency of MHPP, which remains stable and quickly returns to its original frequency. Even the integrated control system is able to respond faster without exceeding the standard frequency droop speed of around 5\%. In this occation, the load is changing in various loads. Originally it is set in full load $82 \mathrm{KW}$, then reduces $20 \mathrm{KW}$ to $62 \mathrm{KW}$, increases $10 \mathrm{KW}$ to $72 \mathrm{KW}$, decreses $40 \mathrm{KW}$ to $32 \mathrm{KW}$, and continue reduces to $12 \mathrm{KW}$. If this results compare to the system frequency with ELC in Fig. 14, system frequency with the integrated control results in the same amount of load changes $(10 \mathrm{KW})$, generates a lower magnitude of frequency change, in around $0.018 \mathrm{~Hz}$.

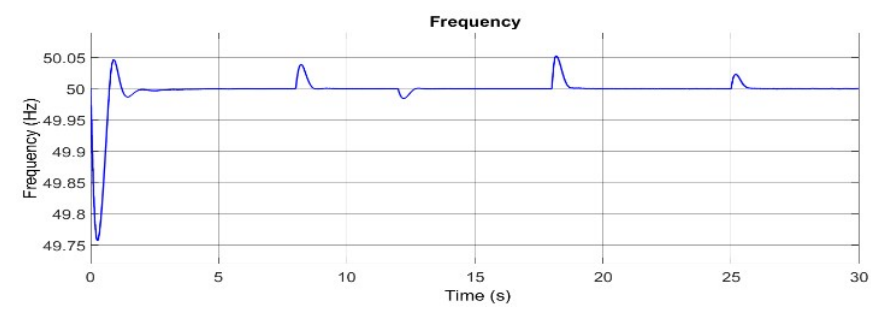

Fig. 19. Frequency of the MHPP with the integrated control system

However, when there is a change in load size up to $40 \mathrm{KW}$ at the $18^{\text {th }}$ second, THD-I of the integrated control system increases significantly compare to the other changes. This happens because a greater ignition angle on the ELC, results a greater harmonics. The most affected harmonics component by the load changes is the $3^{\text {rd }}$ harmonics as in Fig. 20. However, a unique phenomenon of THD-I is found when the load is decreasing from $32 \mathrm{KW}$ to $12 \mathrm{KW}(20 \mathrm{KW})$, the system output results THD-I higher than the load changed from $82 \mathrm{KW}$ to $62 \mathrm{KW}$ as depicted in Table VII.

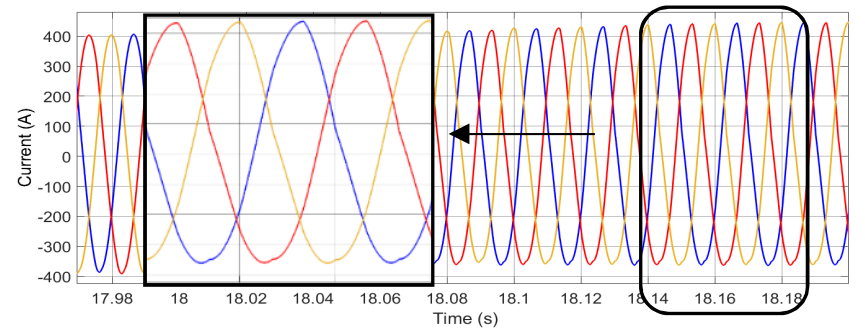

Fig. 20. $3^{\text {rd }}$ THD-I with the integrated control system

TABLE VII. INTEGRATED CONTROL TEST RESUlTS

\begin{tabular}{|c|c|c|c|c|c|}
\hline No & $\begin{array}{c}\text { Consumers } \\
\text { Load (KW) }\end{array}$ & $\begin{array}{c}\text { Ballast } \\
\text { Load } \\
(\mathbf{K W})\end{array}$ & $\begin{array}{c}\text { Total } \\
\text { Power } \\
(\mathbf{K W})\end{array}$ & $\begin{array}{c}\text { Mechanical } \\
\text { Power }(\mathbf{p u})\end{array}$ & THD -I \\
\hline $\mathbf{1}$ & 82 & 0.0 & 100 & 1 & $0.69 \%$ \\
\hline $\mathbf{2}$ & 62 & 10 & 94 & 0.62 & $2.77 \%$ \\
\hline $\mathbf{3}$ & 72 & 0.565 & 95 & 0.63 & $3.91 \%$ \\
\hline $\mathbf{4}$ & 32 & 22.5 & 91 & 0.606 & $7.09 \%$ \\
\hline $\mathbf{5}$ & 12 & 31 & 89.4 & 0.59 & $10.99 \%$ \\
\hline
\end{tabular}

C. Frequency Comparison of FVC with Fuzzy-PI dan PI

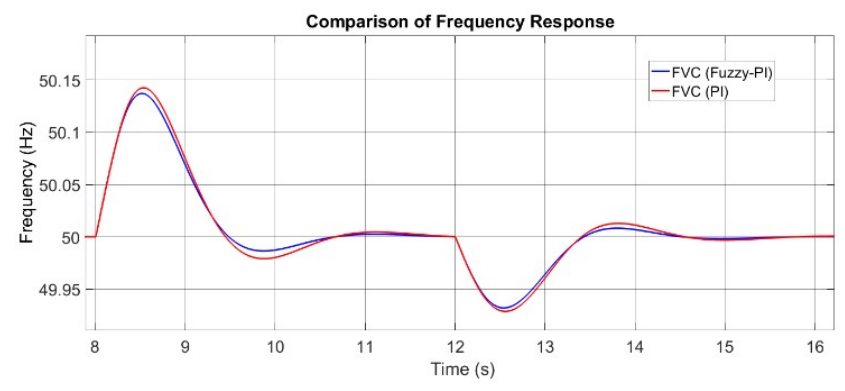

Fig. 21. Frequency comparison of FVC with two different controllers 
For more details observation on the impact of fuzzy-PI controller into the FVC, Fig. 21 shows the difference in MHPP frequency response when using fuzzy-PI and PI, in which the system frequency response uses a fuzzy-PI controller faster when load changes occur. This is because the fuzzy logic controller functions to correct the initial $K p$ and $K i$ parameters so that they get the most appropriate values for the PI. Results in Fig. 21 is justified in detail by data in Table VIII.

TABLE VIII. FreQUENCY PERformanCE COMPARISON OF FVC

\begin{tabular}{|l|c|c|}
\hline \multirow{2}{*}{ Parameter } & \multicolumn{2}{|c|}{ Value } \\
\cline { 2 - 3 } & Fuzzy-PI & PI \\
\hline Settling Time $(\mathrm{s})$ & 5.5459 & 5.563 \\
\hline Settling Min $(\mathrm{Hz})$ & 49.9319 & 49.9286 \\
\hline Settling Max $(\mathrm{Hz}$ & 50.2584 & 50.2668 \\
\hline Overshoot $(\%)$ & 0.5165 & 0.5336 \\
\hline Peak $(\mathrm{Hz})$ & 50.2584 & 50.2668 \\
\hline
\end{tabular}

D. Frequency Comparison of ANFIS-PID dan PID

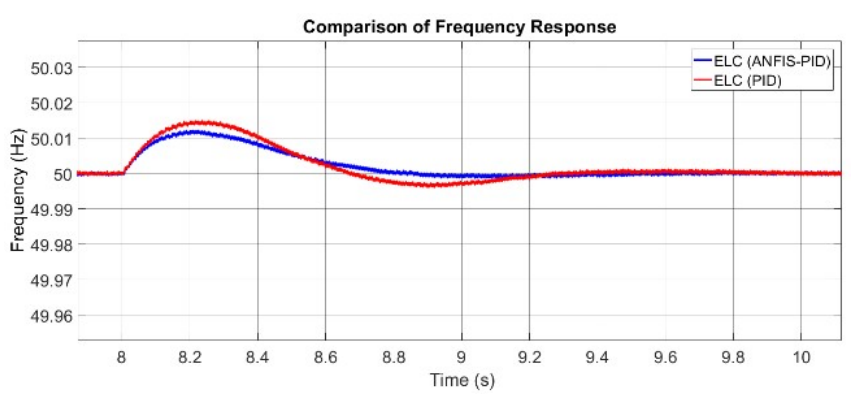

Fig. 22. Frequency comparison of ELC with two different controllers

In order to compare capability of ANFIS-PID to PID for ELC improvement, Fig. 22 shows the difference in frequency response between ANFIS-PID and PID, in which ANFIS-PID has a faster response. This is because the ANFIS capable to predict the training data, such that it can obtain more suitable parameters for PID controller in responding the load changes, Results in Fig. 22 has been justified by Table IX.

TABLE IX. FreQuenCy PERFormanCE COMPARISON OF ELC

\begin{tabular}{|l|c|c|}
\hline \multirow{2}{*}{ Parameter } & \multicolumn{2}{|c|}{ Value } \\
\cline { 2 - 3 } & Fuzzy-PI & PI \\
\hline Settling Time $(\mathrm{s})$ & 5.5459 & 5.563 \\
\hline Settling Min $(\mathrm{Hz})$ & 49.9319 & 49.9286 \\
\hline Settling Max $(\mathrm{Hz}$ & 50.2584 & 50.2668 \\
\hline Overshoot $(\%)$ & 0.5165 & 0.5336 \\
\hline Peak $(\mathrm{Hz})$ & 50.2584 & 50.2668 \\
\hline
\end{tabular}

\section{E. Frequency Comparison of Integrated FVC and ELC}

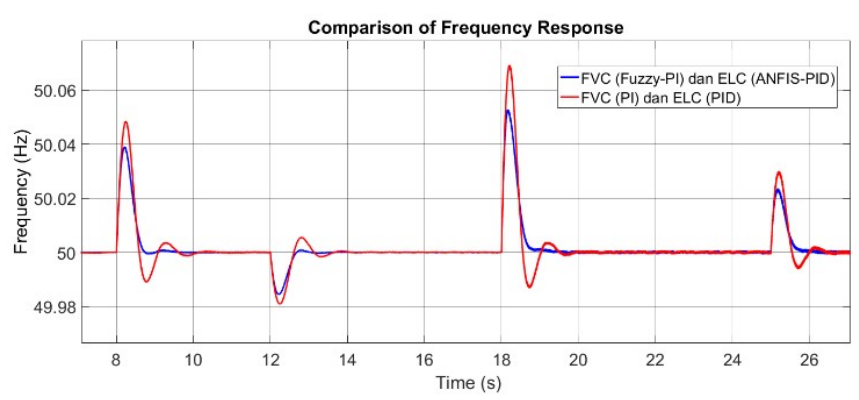

Fig. 23. Frequency the integrated control with the proposed algorithm

When the proposed controller for FVC and ELC are integrated, the performance of the integrated control with the proposed controller was better than the integration without ANFIS and Fuzzy in each of the control systems as in Fig 23.
The combination of ELC and FVC with their own proposed controller was capable to result a better frequency to response the load changes, event in relatively significant change. This conclusion was supported by the data in Table X.

Table X. Frequency Performance Comparison of Integrated CONTROL

\begin{tabular}{|l|c|c|}
\hline \multirow{2}{*}{ Parameter } & Fuzzy-PI & PI \\
\cline { 2 - 3 } & ANFIS-PID & PID \\
\hline Settling Time $(s)$ & 5.11 & 5.0981 \\
\hline Settling Min $(H z)$ & 49.7569 & 49.712 \\
\hline Settling Max $(\mathrm{Hz}$ & 50.0529 & 50.121 \\
\hline Overshoot $(\%)$ & 0.1066 & 0.2431 \\
\hline Peak $(\mathrm{Hz})$ & 50.0529 & 50.121 \\
\hline
\end{tabular}

IV. CONCLUSION

The MHPP integrated frequency control system has been successfully developed and simulated. The results of the simulation show that the addition of fuzzy-PI and ANFIS-PID methods on the FVC and ELC systems respectively and the integration of both, can improve the MHPP system's frequency performance quickly and produce a lower THD, despite there exist significant changes in consumer load.

\section{REFERENCES}

[1] Schener. L. G, and Tambara. R. V, "Voltage and Frequency Regulation of Standalone Self-excited Induction Generator for Micro-hydro Power Generation using Discrete-time Adaptive Control," IET Renewable Power Generation, vol. 10, no. 4, pp. 531-540, 2016.

[2] Singh. A.K, "Modelling and Simulation of Micro Hydro-Diesel Hybrid Power System for Localized Power Requirement Using MATLAB/Simulink," Thesis, Jadavpur University, 2013.

[3] Usman. A. A and Abdulkadir. R. A, "Modelling and Simulation of Micro Hydro Power Plant using Matlab Simulink," in India, vol. 3, no. 1 (Special issue), 2015.

[4] Zhixue. Z, Zhihong. H., and Zhihuai X., "PID Control with Fuzzy Compensation for Hydroelectric Generating Unit," Proc. of Int. Conf. on Power System Technology, Kunming, China, 2002.

[5] Abdolmaleki. M, Ansarimehr. P, and Ranjbar. A. M, "A Robust Fuzzy Logic Adaptive PI Controller for Hydro Power Plant," SICE Annual Conference, Takamatsu, Japan, 2007.

[6] Zhang X-Y, Zhang M-G., "An Adaptive Fuzzy-PID Control of Hydraulic-Turbine Governor," Proc. of 2006 International Conference on Machine Learning and Cybernetics, Dalian, China, 2006.

[7] Heng. Q, Lu. J, Lu. X, and Cao. H, "Design of Robust Hœ PI Controller Hydro Turbine Speed Governor," Proc. of the $27^{\text {th }}$ Chinese Control and Decision Conference, pp. 2314-2318, Qingdao, China, 2015.

[8] Blooming T. M, Carnovale. D. J, “Application od IEEE STD 519-1992 Harmonic Limit," Conference Record of 2006 Annual Pulp and Paper Technical Conference, Appleton, USA, 2006.

[9] Juang. C. F, Lu. C. F, "Load-frequency control by hybrid evolutionary fuzzy PI controller", IEEE Proceedings-Generation Transmission and Distribution, vol. 153, no. 2, pp. 196-204, 2006.

[10] Pham. D. A, Nollet. F, Essounbouli. N, Hamzaoui. A, "Voltage and Frequency Regulation for Wound Rotor Synchronous Generator in Mycrohydro Power Plants with Real-Time Implementation," Proc. of Int. Renewable and Sustainable Energy Conf., Marocco, Dec 2017.

[11] Datta. A, Bhattcharjee. K, Debbarma. S, Kar. B, and "Load Frequency Control of a Renewable Energy Sources Based Hybrid Systems', Proc. of IEEE Conference on Systems, Process, and Control, Malaysia, 2015.

[12] Ali M. and Sodiq. D, "Analisa Harmonisa Electronic Load Controller pada PLMH”, Poli-Teknologi Politeknik Negeri Bandung, vol. 10, no. 2, 2011.

[13] Brezovac. M, Kuzle. I, and Krpan. M, "Detailed Mathematical and Simulation Model of a Synchronous Generator," Journal of Energy, vol. 64 (2015) Special issue, pp. 102-129, 2015.

[14] 421.5-2016-"IEEE Recommended Practice for Excitation System Models for Power System Stability Studies," Revision of IEEE Std 421.5-2005 (Revision of IEEE Std 521.5-1992). 